\title{
SUMBER STRES, STRATEGI KOPING, DAN TINGKAT STRES PADA BURUH PEREMPUAN BERSTATUS MENIKAH DAN LAJANG
}

\author{
Ria Oktarina ${ }^{1^{*}}$, Diah Krisnatuti ${ }^{2}$, Istiqlaliyah Muflikhati ${ }^{2}$ \\ ${ }^{1}$ Program Studi Ilmu Keluarga dan Perkembangan Anak, Sekolah Pascasarjana, Institut Pertanian Bogor, \\ Bogor 16680, Indonesia
${ }^{2}$ Departemen IImu Keluarga dan Konsumen, Fakultas Ekologi Manusia, Institut Pertanian Bogor, \\ Bogor 16680, Indonesia \\ *)E-mail: riaoktarina53@yahoo.co.id
}

\begin{abstract}
Abstrak
Penelitian ini bertujuan untuk menganalisis perbedaan antara karakteristik, sumber stres, strategi koping, dan tingkat stres buruh perempuan berdasarkan status pernikahan (menikah dan lajang) dan untuk menganalisis pengaruh karakteristik, sumber stres, dan strategi koping terhadap tingkat stres buruh perempuan. Penelitian dilakukan di pabrik garmen TBG, Kota Bogor, Jawa Barat. Penelitian melibatkan 120 buruh perempuan (60 buruh perempuan berstatus menikah dan 60 buruh perempuan berstatus lajang) yang dipilih secara stratified random sampling. Data dikumpulkan dengan wawancara dan dianalisis dengan analisis deskriptif, uji beda $t$, dan uji regresi linear berganda. Hasil penelitian menunjukkan bahwa usia, pendapatan, sumber stres, dan strategi koping buruh perempuan menikah lebih tinggi dibandingkan dengan buruh perempuan lajang, sedangkan tingkat stres buruh perempuan menikah lebih rendah dibandingkan dengan buruh perempuan lajang. Tingkat stres buruh perempuan dipengaruhi oleh pendapatan per kapita dan strategi koping fokus emosi. Pertambahan pendapatan per kapita dan strategi koping fokus emosi dapat menurunkan tingkat stres buruh perempuan.
\end{abstract}

Kata kunci: status pernikahan, strategi koping, sumber stres, tingkat stres

\section{Sources of Stress, Coping Strategies, and Stress Level of Women Workers Who Married and Single}

\begin{abstract}
Abstrack
This study aimed to analyze the differences between characteristics, sources of stress, coping strategies, and stress level based on marital status (married and single) and also to analyze the influence of characteristics, sources of stress, and coping strategies on stress levels of women workers. The study was conducted in the TBG garment factory, Bogor City, West Java. The study involved 120 women workers (60 married women workers and 60 single women workers) that was selected by stratified random sampling. Data was collected by interview and was analyzed by descriptive analysis, independent samples t-test, and multiple linear regression. The results showed that age, income, sources of stress, and coping strategies of married woman worker was higher than single women worker, whereas stress level of married women worker is lower than single women worker. The increasing of income per capita and emotional focus coping can decrease stress level of women worker.
\end{abstract}

Keywords: coping strategies, marital status, sources of stress, stress level

\section{PENDAHULUAN}

Bekerja sebagai buruh memiliki tantangan tersendiri terutama bagi perempuan karena perempuan memiliki peran ganda antara keluarga dan pekerjaan. Salah satu alasan perempuan bekerja adalah harapan untuk mencapai kemandirian ekonomi dan tidak mempedulikan jabatan manajerial (WellsParker, Miller, \& Topping, 1990). Serikat Pekerja Nasional (SPN) menyatakan bahwa sekitar 70 persen buruh di sektor tekstil, garmen, dan sepatu adalah perempuan (Tambunan, 2007).
Berdasarkan hasil riset Forum Pendamping Buruh Nasional (FPBN) tahun 2005-2006 menunjukkan bahwa dari 92 perusahaan yang berada di wilayah Tangerang dan Bekasi sebanyak 62 persen diantaranya menggunakan tenaga buruh kontrak dan lebih dari 50 persen adalah buruh perempuan (Puspitawati, Simanjuntak, \& Hayati, 2012). Terjadinya peningkatan pekerja perempuan, menyebabkan banyak perusahaan lebih memilih untuk mempekerjakan pekerja lajang karena selalu siap dan tidak memiliki beban keluarga. Hutagalung et al. (1992) menemukan bahwa buruh wanita di industri besar 
umumnya lajang atau janda tanpa anak. Selain itu, perempuan lebih disukai perusahaan karena tidak banyak menuntut dan mudah dikendalikan serta mau dibayar murah.

Smet (1994) mengidentifikasi keluarga dan pekerjaan sebagai sumber stres. Stres kerja dapat disebabkan lingkungan fisik yang telalu menekan seperti kebisingan, temperatur atau panas yang terlalu tinggi, udara yang lembab, penerangan di kantor yang kurang terang (Smet, 1994; Duxburry \& Higgins, 1991). Stres keluarga (family stress) dapat berupa suatu gangguan terhadap keadaan keluarga yang sudah mapan (steady state), menciptakan ketidaktenangan, atau menimbulkan tekanan (Sussman \& Steinmetz, 1987). Kurangnya dukungan sosial dari keluarga dapat menyebabkan konflik antara keluarga dan pekerjaan (Carlson \& Perrewe, 1999; Greenhaus \& Beutell, 1985; Yang, Chen, \& Zou, 2000). Bagi perempuan yang tidak dapat mencapai keseimbangan keluarga dan pekerjaan akan muncul masalah konflik yang berlangsung terus-menerus akan berdampak pada kelelahan fisik dan mental (Burke, 1994; Burke \& Greenglass, 2001; Kossek \& Ozeki, 1999). Perempuan menikah lebih banyak mengalami konflik antara keluarga dan pekerjaan, dibandingkan dengan perempuan lajang, hal ini dapat menyebabkan stres khususnya bagi buruh perempuan (Greenhaus \& Beutell, 1985). Perempuan menikah yang bekerja menghadapi lebih banyak persoalan terkait dengan peran yang dihadapi, yaitu sebagai istri, ibu, pengurus rumah tangga dan seorang pekerja (Ahmad, 1995). Hal inilah yang menyebabkan stres bagi buruh perempuan.

Agar tidak timbul stres kerja diperlukan suatu upaya untuk menanggulanginya antara lain dengan strategi koping. Strategi koping merupakan suatu upaya mengatasi stres yang memerlukan proses kognitif dan afektif untuk menyesuaikan diri terhadap stres dan bukan memberantas stres. Jenis strategi koping yang biasa dilakukan menghadapi stres yaitu strategi koping fokus masalah (problem focus coping) dan strategi koping fokus emosi (emotional focus coping). Strategi koping fokus masalah adalah pengendalian dalam mengatasi stres dengan mengubah masalah yang dihadapi dan lingkungan sekitarnya yang menyebabkan terjadinya tekanan, sedangkan strategi koping fokus emosi adalah usaha mengatasi stres dengan cara mengatur emosi dalam menyesuaikan diri dari dampak yang ditimbulkan oleh suatu kondisi dan situasi yang dianggap penuh tekanan (Lazarus et al., 1986; Zakowski, Hall, \& Klein, 2001). Perbedaan tingkat stres merupakan salah satu faktor pembeda dalam melakukan koping (Sussman \& Steinmentz, 1987).

Sebuah survei pada pekerja di Amerika Serikat menemukan bahwa 46 persen pekerja merasakan pekerjaan mereka penuh dengan stres dan tiga puluh empat persen pekerja berpikir untuk keluar dari pekerjaan mereka 12 bulan sebelumnya karena stres di tempat kerja (Sasono, 2004). International Labour Organization (ILO), diacu dalam Koswara (2009) di United Kingdom melaporkan bahwa tiga dari sepuluh pekerja mengalami masalah mental. Di Finlandia, tujuh persen dari tenaga kerja menderita gejala yang berhubungan dengan stres. ILO memperkirakan bahwa stres dalam pekerjaan yang terjadi di dunia mengeluarkan biaya di atas $\$ 200$ Milyar per tahun.

Berdasarkan pemaparan tersebut, penelitian ini bertujuan untuk menganalisis perbedaan antara karakteristik, sumber stres, strategi koping, dan tingkat stres buruh perempuan berdasarkan status pernikahan (menikah dan lajang). Selain itu, penelitian ini juga bertujuan untuk menganalisis pengaruh karakteristik, sumber stres, dan strategi koping terhadap tingkat stres buruh perempuan.

\section{METODE}

Penelitian ini menggunakan desain cross sectional. Lokasi penelitian dipilih secara purposive yaitu di pabrik garmen TBG, Kecamatan Bogor Barat, Kota Bogor, Provinsi Jawa Barat. TBG merupakan salah satu pabrik garmen yang mempekerjakan buruh perempuan. Waktu penelitian dimulai dari bulan Maret sampai dengan bulan April 2015.

Populasi dalam penelitian ini adalah seluruh buruh perempuan yang bekerja di TBG, yaitu sebanyak 513 orang (terdiri atas 247 orang buruh berstatus lajang dan 266 berstatus menikah). Contoh dipilih menggunakan teknik stratified random sampling. Contoh yang terlibat berjumlah 120 buruh perempuan, terdiri atas 60 buruh perempuan yang berstatus menikah dan 60 buruh perempuan yang berstatus lajang.

Data primer diperoleh melalui teknik wawancara dengan alat bantu kuesioner. Data yang dikumpulkan meliputi data karakteristik individu, sumber stres, strategi koping, dan tingkat stres. Karakteristik individu terdiri atas status pernikahan, usia, pendidikan, pendapatan, masa kerja (lama kerja), dan pendapatan per kapita per bulan. 
Sumber stres merupakan cara pandang buruh terhadap sumber stres yang ditimbulkan dari lingkungan pekerjaan dan lingkungan keluarga. Di lingkungan pekerjaan seperti merasa tertekan dengan kondisi lingkungan fisik seperti luas ruangan, pertukaran udara, pencahayaan, dan di lingkungan keluarga seperti merasa tertekan dengan tuntutan keluarga untuk waktu berkumpul bersama dan liburan bersama. Instrumen yang digunakan untuk mengukur sumber stres dimodifikasi dari instrumen yang disusun oleh Koswara (2009). Instrumen ini telah reliabel dengan nilai Cronbach's alpha sebesar 0,812. Instrumen ini terdiri atas 20 pertanyaan dengan pilihan jawaban (1) tidak membuat saya tertekan, (2) membuat saya agak tertekan, (3) membuat saya tertekan, dan (4) membuat saya sangat tertekan. Skor yang diperoleh kemudian dihitung indeksnya dan dikategorikan menjadi tiga kategori, yaitu rendah (indeks 0,0-60,0), sedang (indeks $60,0-80,0$ ), dan tinggi (indeks 80,0-100,0).

Strategi koping adalah upaya adaptasi yang dilakukan buruh terhadap sumber stres dengan cara berfokus pada masalah (problem focused coping) dan strategi koping berfokus pada emosi (emotional focused coping). Instrumen yang digunakan untuk mengukur strategi koping dimodifikasi dari instrumen yang disusun oleh Lazarus et al. (1986). Instrumen ini telah reliabel dengan nilai Cronbach's alpha sebesar 0,900. Instrumen ini terdiri atas 20 pertanyaan dengan dengan pilihan jawaban (1) sangat tidak setuju, (2) tidak setuju, (3) setuju, dan (4) sangat setuju. Skor yang diperoleh kemudian dihitung indeksnya dan dikategorikan menjadi tiga kategori, yaitu rendah (indeks 0,060,0 ), sedang (indeks $60,0-80,0$ ), dan tinggi (indeks 60,0-80,0).

Variabel selanjutnya yang dianalisis adalah tingkat stres. Stres dapat diketahui dengan memperhatikan gejala yang diperlihatkan, baik gejala fisik maupun gejala emosional. Stres sebagai suatu kondisi yang disebabkan oleh transaksi individu dengan lingkungan yang menimbulkan persepsi jarak antara tuntutantuntutan yang berasal dari situasi dengan sumber daya sistem biologis, psikologis, dan sosial seseorang (Safarino, 1994). Tingkat stres diukur berdasarkan gejala-gejala penyakit yang dapat menyebabkan stres. Tingkat stres diukur mengunakan instrumen yang disusun oleh Ebel et al. (1983). Instrumen ini telah reliabel dengan nilai Cronbach's alpha sebesar 0,874. Instrumen ini terdiri atas 37 pertanyaan dengan dengan pilihan jawaban (1) tidak pernah, (2) jarang (bila lebih dari 1 kali setiap 6 bulan), (3) sering (jika lebih dari 1 kali setiap bulan), (4) sangat sering (jika lebih dari 1 kali setiap minggu), dan (5) selalu (jika terjadi setiap hari). Skor yang diperoleh dijumlahkan dan dikelompokkan menjadi tiga kategori yaitu rendah (37-71), sedang (72-96), dan tinggi $(\geq 97)$.

Data yang diperoleh diolah dan dianalisis secara deskriptif dan inferensial. Analisis data yang digunakan adalah analisis deskriptif, uji beda $t$, dan uji regresi linier berganda. Analisis deskriptif digunakan untuk menghitung kategori, nilai minimum, nilai maksimum, nilai rata-rata, dan standar deviasi. Uji beda t digunakan untuk melihat perbedaan karakteristik, sumber stres, strategi koping, dan tingkat stres antara buruh perempuan menikah dan lajang. Selanjutnya, uji regresi linier berganda digunakan untuk menganalisis pengaruh karakteristik, sumber stres, dan strategi koping terhadap tingkat stres buruh perempuan.

\section{HASIL}

\section{Karakteristik Buruh Perempuan}

Variabel karakteristik buruh perempuan terdiri atas usia, masa kerja (lama kerja), pendapatan per bulan dan pendapatan per kapita per bulan. Hasil penelitian pada Tabel 1 menunjukkan bahwa rata-rata usia buruh perempuan lajang adalah 19,8 tahun dan ratarata sudah bekerja selama 1,8 tahun dengan rata-rata pendapatan per bulan sebesar Rp1.207.600 serta rata-rata pendapatan per kapita sebesar Rp546.831 per bulan. Sementara itu, buruh perempuan menikah memiliki rata-rata usia 26,7 tahun dan rata-rata lama kerja 1,9 tahun dengan rata-rata pendapatan sebesar Rp1.405.566 per bulan serta memiliki rata-rata pendapatan per kapita per bulan sebesar Rp670.025.

Tabel 1 Nilai rata-rata, standar deviasi, dan koefesiensi uji beda karakteristik buruh perempuan berstatus menikah dan lajang

\begin{tabular}{lccl}
\hline \multirow{2}{*}{$\begin{array}{l}\text { Karakteristik } \\
\text { buruh }\end{array}$} & \multicolumn{2}{c}{$\begin{array}{c}\text { Rata-rata } \pm \text { deviandar } \\
\text { deviasi }\end{array}$} & p-value \\
\cline { 2 - 3 } & Lajang & Menikah & \\
\hline Usia (tahun) & $19,8 \pm 2,8$ & $26,7 \pm 5,45$ & $0,000^{* *}$ \\
Lama kerja & $1,8 \pm 1,8$ & $1,9 \pm 0,9$ & 0,257 \\
(tahun) & & & \\
Pendapatan & $1.207 .600 \pm$ & $1.405 .566 \pm$ & $0,000^{* *}$ \\
(Rp/ bulan) & 226.779 & 281.640 & \\
Pendapatan & $546.831 \pm$ & $670.025 \pm$ & $0,029^{*}$ \\
per kapita & 234355 & 364.124 & \\
(Rp/ bulan) & & & \\
\hline $\begin{array}{l}\text { Keterangan: } \\
\text { **signifikan pada } p<0,1 ;{ }^{*} \text { signifikan pada } p<0,05\end{array}$ &
\end{tabular}


Hasil uji beda t yang disajikan pada Tabel 1 menunjukkan bahwa usia, pendapatan per bulan, dan pendapatan per kapita per bulan antara buruh perempuan yang menikah dan lajang berbeda secara signifikan $(p<0,05)$, sedangkan lama kerja tidak berbeda secara signifikan ( $p>0,05)$. Rata-rata usia, pendapatan, dan pendapatan per kapita per bulan pada buruh perempuan menikah lebih tinggi dibandingkan dengan buruh perempuan lajang.

\section{Sumber Stres}

Sumber stres dibagi menjadi dua, yaitu sumber stres dari lingkungan pekerjaan dan lingkungan keluarga (Tabel 2). Stres pekerjaan merupakan respon fisikal dan emosional yang berbahaya dan yang terjadi bila persyaratanpersyaratan pekerjaan tidak cocok dengan kemampuan, sumber daya, dan kebutuhan pekerja. Menurut Smet (1994) faktor-faktor yang membuat pekerjaan menjadi stres adalah tuntutan pekerjaan (pekerjaan terlalu banyak dan keharusan menyelesaikan pekerjaan dalam waktu tertentu), jenis pekerjaan itu sendiri yang bersifat stres, dan tanggung jawab bagi kehidupan manusia.

Pada dimensi lingkungan pekerjaan menunjukkan bahwa kurang dari separuh buruh perempuan menikah $(48,3 \%)$ dan lebih dari tiga perlima buruh perempuan lajang (63,3\%) mempersepsikan stres berada pada kategori sedang (indeks 60,0-80,0). Hasil uji beda menemukan sumber stres tidak berbeda secara signifikan $(p>0,05)$ antara buruh perempuan menikah dan lajang. Meskipun buruh perempuan menikah lebih merasa tertekan dengan kondisi fisik tempat kerja, beban tugas pekerjaan yang harus dilaksanakan, lamanya jam kerja di tempat kerja, dan ketika atasan memberikan penilaian terhadap hasil kerja.

Sumber stres dari lingkungan keluarga merupakan suatu gangguan terhadap keadaan keluarga yang sudah mapan (steady stage) yang mencakup segala sesuatu yang dapat mengganggu keluarga, menciptakan ketidaktenangan atau menimbulkan tekanan-tekanan pada keluarga (Sussman \& Steinmetz, 1987). Pada dimensi lingkungan keluarga buruh perempuan menikah $(91,7 \%)$ berada pada kategori tinggi (indeks 80,0-100,0), sedangkan stres dari lingkungan keluarga pada buruh perempuan lajang $(43,3 \%)$ berada pada kategori rendah (Tabel 2 ).

Hasil analisis uji beda pada penelitian ini menemukan bahwa sumber stres dari lingkungan keluarga antara buruh perempuan menikah dan lajang berbeda signifikan $(p<0,01)$. Stres dari lingkungan keluarga pada buruh perempuan menikah lebih tinggi dibandingkan dengan buruh perempuan lajang. Buruh perempuan menikah merasa tertekan dengan beban tugas sebagai istri, ibu, sedikitnya waktu yang tersedia untuk istirahat di rumah, tuntutan keluarga, terjadinya konflik peranan di dalam keluarga, tidak terlibat dalam proses pengambilan keputusan dalam keluarga, dan ketika mengalami kekesalan di dalam keluarga.

Secara umum, hasil penelitian menunjukkan bahwa pada sumber stres total buruh perempuan menikah (55\%) dan lajang $(66,7 \%)$ termasuk dalam kategori sedang (indeks 60,0-80,0). Hasil uji beda dalam penelitian ini menemukan bahwa sumber stres total antara buruh perempuan menikah dan lajang berbeda secara signifikan $(p<0,01)$. Sumber stres baik dari lingkungan pekerjaan maupun keluarga pada buruh perempuan menikah lebih besar dibandingkan dengan buruh perempuan lajang.

Tabel 2 Sebaran buruh perempuan berdasarkan kategori sumber stres

\begin{tabular}{|c|c|c|}
\hline Sumber stres & $\begin{array}{c}\text { Lajang } \\
(\%)\end{array}$ & $\begin{array}{c}\text { Menikah } \\
(\%)\end{array}$ \\
\hline \multicolumn{3}{|l|}{ Lingkungan pekerjaan } \\
\hline Rendah (indeks<60) & 11,7 & 16,7 \\
\hline Sedang (indeks 60-80) & 63,3 & 48,3 \\
\hline Tinggi (indeks $>80$ ) & 25,0 & 35,0 \\
\hline Total & 100,0 & 100,0 \\
\hline Minimum-maksimum & $35-94$ & $38-100$ \\
\hline $\begin{array}{l}\text { Rata-rata } \pm \text { Standar } \\
\text { deviasi }\end{array}$ & $72,2 \pm 12,4$ & $74,7 \pm 15,6$ \\
\hline$p$-value & \multicolumn{2}{|c|}{0,347} \\
\hline \multicolumn{3}{|l|}{ Lingkungan keluarga } \\
\hline Rendah (indeks $<60$ ) & 43,3 & 3,3 \\
\hline Sedang (indeks 60-80) & 31,7 & 5,0 \\
\hline Tinggi (indeks>80) & 25,0 & 91,7 \\
\hline Total & 100,0 & 100,0 \\
\hline Minimum-maksimum & $38-85$ & $38-90$ \\
\hline $\begin{array}{l}\text { Rata-rata } \pm \text { Standar } \\
\text { deviasi }\end{array}$ & $64,9 \pm 13,3$ & $80,1 \pm 9,4$ \\
\hline$p$-value & \multicolumn{2}{|c|}{$0,000^{* *}$} \\
\hline \multicolumn{3}{|l|}{ Sumber stres } \\
\hline Rendah (indeks<60) & 15,0 & 3,3 \\
\hline Sedang (indeks 60-80) & 66,7 & 55,0 \\
\hline Tinggi (indeks>80) & 18,3 & 41,7 \\
\hline Total & 100,0 & 100.0 \\
\hline Minimum-maksimum & $41-87$ & $53-92$ \\
\hline $\begin{array}{l}\text { Rata-rata } \pm \text { Standar } \\
\text { deviasi }\end{array}$ & $68,6 \pm 10,0$ & $77,52 \pm 9,5$ \\
\hline$p$-value & \multicolumn{2}{|c|}{$0,000^{* *}$} \\
\hline
\end{tabular}

\footnotetext{
Keterangan:

${ }^{* *}$ signifikan pada $\mathrm{p}<0,01 ; \%=$ persentase
} 


\section{Strategi Koping}

Strategi koping yang dianalisis dalam penelitian ini terdiri atas dua jenis strategi koping, yaitu strategi koping berfokus pada masalah (problem focused coping) dan strategi koping yang berfokus pada emosi (emotional focused coping). Rata-rata skor dan koefisien uji beda strategi koping pada buruh perempuan menikah dan lajang disajikan pada Tabel 3.

Hasil analisis uji beda menunjukkan bahwa strategi koping berfokus masalah antara buruh perempuan menikah dan lajang berbeda signifikan $(p<0,01)$. Nilai rata-rata strategi koping berfokus masalah pada buruh perempuan menikah lebih tinggi dibandingkan dengan buruh perempuan lajang (Tabel 3). Buruh perempuan menikah bekerja keras agar berhasil, membuat suatu perencanaan setiap pekerjaan, mengubah sesuatu untuk menjadi lebih baik, berbicara pada (pasangan, keluarga besar, teman) suatu masalah dan kemudian meminta saran.

Selanjutnya, strategi koping yang dianalisis pada penelitian ini adalah strategi koping berfokus pada emosi. Hasil uji beda menemukan bahwa strategi koping berfokus pada emosi antara buruh perempuan menikah dan lajang berbeda signifikan $(p<0,01)$. Nilai rata-rata skor strategi koping berfokus emosi pada buruh perempuan menikah lebih tinggi dibandingkan dengan buruh perempuan lajang (Tabel 3). Hasil uji beda pada penelitian ini menemukan bahwa terdapat perbedaan yang signifikan $(p<0,01)$ pada strategi koping secara total antara buruh perempuan menikah dan lajang, yang mana buruh perempuan menikah lebih tinggi dibandingkan dengan buruh perempuan lajang. Buruh perempuan menikah memikirkan terlebih dahulu apa yang hendak dikatakan dan menjaga agar orang lain tidak mengetahui seberapa buruk masalah yang sedang dihadapi.

Tabel 3 Rata-rata skor dan koefisien uji beda strategi koping pada buruh perempuan menikah dan lajang

\begin{tabular}{lrrr}
\hline \multirow{2}{*}{ Strategi koping } & \multicolumn{2}{c}{ Rata-rata skor } & \multirow{2}{*}{-value } \\
\cline { 2 - 3 } & Lajang & Menikah & \\
\hline $\begin{array}{l}\text { Strategi koping } \\
\text { berfokus pada } \\
\text { masalah }\end{array}$ & 74,4 & 87,1 & $0,000^{* *}$ \\
$\begin{array}{l}\text { Strategi koping } \\
\text { berfokus pada }\end{array}$ & 48,6 & 68,5 & $0,001^{* *}$ \\
$\begin{array}{l}\text { emosi } \\
\begin{array}{l}\text { Strategi koping } \\
\text { total }\end{array}\end{array}$ & 123,5 & 155,9 & $0,000^{* *}$ \\
\hline $\begin{array}{l}\text { Keterangan: } \\
{ }^{* *} \text { signifikan pada } p<0,01\end{array}$ & & \\
\end{tabular}

\section{Tingkat Stres Buruh Perempuan}

Persentase tertinggi tingkat stres buruh perempuan baik yang menikah $(50,0 \%)$ maupun lajang $(65,0 \%)$ termasuk dalam kategori rendah (Tabel 4). Tingkat stres antara buruh perempuan menikah dan lajang berbeda signifikan $(p<0,05)$. Nilai rata-rata untuk tingkat stres buruh perempuan lajang lebih tinggi daripada buruh perempuan menikah. Buruh perempuan lajang lebih sering mengalami gejala-gejala penyakit pada saat bekerja daripada buruh perempuan menikah, seperti sakit perut, tangan dingin, mulut kering, kulit berjerawat, kulit berminyak terutama muka, dan sering kencing.

\section{Pengaruh Karakteristik, Sumber Stres, dan Strategi Koping terhadap Tingkat Stres Buruh Perempuan}

Pengaruh karakteristik, sumber stres, dan strategi koping terhadap tingkat stres buruh perempuan dianalisis dengan menggunakan uji regresi linier berganda. Model yang dibangun memiliki koefisien determinasi (Adjusted $R$ Square) sebesar 0,118 (Tabel 5). Koefisien tersebut menunjukkan bahwa sebesar 11,8 persen tingkat stres buruh perempuan dipengaruhi oleh karakteristik, sumber stres, dan strategi koping. Sementara itu, sisanya sebesar 82,2 persen tingkat stres dipengaruhi oleh faktor-faktor lain yang tidak diamati dalam penelitian ini. Tingkat stres buruh perempuan dipengaruhi oleh pendapatan per kapita per bulan $(\beta=-8,037, \quad p<0,1)$. Hasil ini mengindikasikan bahwa bertambahnya pendapatan per kapita per bulan dapat menurunkan tingkat stres buruh perempuan. Selain itu, tingkat stres buruh perempuan dipengaruhi oleh strategi koping fokus emosi $(\beta=-0,117, p<0,05)$. Hasil ini mengindikasikan bahwa peningkatan strategi koping dapat menurunkan tingkat stres buruh perempuan.

Tabel 4 Kategori, nilai minimum dan maksimum, nilai rata-rata dan standar deviasi, serta koefisien uji beda tingkat stres buruh perempuan menikah dan lajang

\begin{tabular}{lrr}
\hline \multicolumn{2}{l}{ Tingkat stres buruh } & \multicolumn{2}{c}{ Lajang (\%) } & Menikah (\%) \\
\hline Rendah (skor 37-71) & 50,0 & 65,0 \\
Sedang (skor 72-96) & 43,3 & 33,3 \\
Tinggi (skor >97) & 6,7 & 1,7 \\
Total & 100,0 & 100,0 \\
Minimum-maksimum & $46-111$ & $43-100$ \\
Rata-rata \pm Standar & $70,9 \pm 13,99$ & $65,5 \pm 12,9$ \\
deviasi & \multicolumn{2}{c}{$0.030^{*}$} \\
p-value & \multicolumn{2}{c}{} \\
\hline Keterangan : \\
\%=persentase; *signifikan pada p<0,05
\end{tabular}


Tabel 5 Koefisien regresi karakteristik responden, sumber stres, dan strategi koping terhadap tingkat stres buruh perempuan

\begin{tabular}{|c|c|c|}
\hline Variabel & $\operatorname{Exp}(\mathrm{B})$ & Sig. \\
\hline Konstanta & 71,920 & $0,000^{* * *}$ \\
\hline \multicolumn{3}{|l|}{ Karakteristik } \\
\hline $\begin{array}{l}\text { Status pernikahan } \\
\text { ( } 0=\text { laiang, } 1=\text { menikah) }\end{array}$ & $-1,544$ & 0,678 \\
\hline Usia responden (tahun) & $-0,182$ & 0,543 \\
\hline Masa kerja (tahun) & $-0,358$ & 0,826 \\
\hline $\begin{array}{l}\text { Pendidikan responden } \\
(0=\text { tidak tamat SMP, } \\
1=\text { tamat SMP }\end{array}$ & 2,001 & 0,441 \\
\hline $\begin{array}{l}\text { Pendapatan responden } \\
\text { (Rp/bulan) }\end{array}$ & $-7,083$ & 0,204 \\
\hline $\begin{array}{l}\text { Pendapatan per kapita } \\
\text { (Rp/bulan) } \\
\text { Sumber stres }\end{array}$ & $-8,037$ & $0,058^{*}$ \\
\hline $\begin{array}{l}\text { Lingkungan pekerjaan } \\
\text { (indeks) }\end{array}$ & 0,116 & 0,187 \\
\hline $\begin{array}{l}\text { Lingkungan keluarga } \\
\text { (indeks) }\end{array}$ & 0,035 & 0,741 \\
\hline \multicolumn{3}{|l|}{ Strategi koping } \\
\hline $\begin{array}{l}\text { Problem focus coping } \\
\text { (skor) }\end{array}$ & $-0,098$ & 0,321 \\
\hline $\begin{array}{l}\text { Emotional focus coping } \\
\text { (skor) }\end{array}$ & $-0,117$ & $0,013^{\star *}$ \\
\hline $\mathrm{R}^{2}$ & \multicolumn{2}{|c|}{0,192} \\
\hline Adjusted R Square & \multicolumn{2}{|c|}{0,118} \\
\hline $\mathrm{F}$ & \multicolumn{2}{|c|}{2,596} \\
\hline Sig. & \multicolumn{2}{|c|}{0,007} \\
\hline 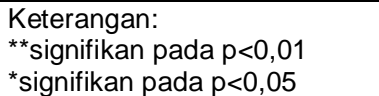 & & \\
\hline
\end{tabular}

\section{PEMBAHASAN}

Sumber stres pada dasarnya menyangkut penilaian buruh terhadap stres yang dialami. Berat atau tidaknya suatu stres ditentukan oleh tinggi dan rendahnya ancaman yang berasal dari suatu peristiwa atau transisi. Hasil penelitian ini menunjukkan bahwa sumber stres pada buruh perempuan menikah dan lajang tidak berpengaruh signifikan terhadap tingkat stres. Sumber stres buruh perempuan yang sudah menikah baik dari lingkungan pekerjaan maupun lingkungan keluarga lebih tinggi dibandingkan dengan buruh perempuan lajang. Buruh perempuan yang sudah menikah merasa tertekan dengan lingkungan pekerjaan seperti kondisi fisik tempat kerja, beban tugas pekerjaan yang harus dilaksanakan, lamanya jam kerja ditempat kerja, dan ketika atasan memberikan penilaian terhadap hasil kerja. Adapun pada lingkungan keluarga yang mana buruh perempuan menikah merasa tertekan dengan sedikitnya waktu yang tersedia untuk istirahat di rumah, tuntutan keluarga, terjadinya konflik peranan di dalam keluarga, tidak terlibat dalam proses pengambilan keputusan dalam keluarga, dan ketika mengalami kekesalan di dalam keluarga.
Buruh perempuan yang sudah menikah menghadapi konflik peran antara bekerja sekaligus ibu rumah tangga. Bertemunya dua peran sekaligus yang terjadi pada buruh perempuan yang berstatus menikah akan menciptakan tekanan-tekanan psikologis yang akan berdampak pada kinerja buruh perempuan tersebut. Apabila kedua peran tersebut tidak dapat dipenuhi dalam waktu yang bersamaan maka saat itulah akan timbul konflik, baik yang berasal dari keluarga maupun yang berasal dari pekerjaan. Greenhaus dan Beutell (1985) menjelaskan konflik antarperan terjadi ketika pelaksanaan salah satu peran menyulitkan pelaksanaan peran yang lain. Tekanan untuk menyeimbangkan dua peran tersebut dapat menyebabkan timbulnya stres.

\section{Hasil survei yang dilakukan oleh Thomas dan Ganster (1995) menjelaskan bahwa} sebanyak 38 persen pria dan 43 persen perempuan yang telah menikah dan memiliki pekerjaan serta anak dilaporkan mengalami konflik keluarga dan pekerjaan. Buruh perempuan yang memiliki peran ganda merasa tertekan dengan kedisiplinan di tempat kerja yang mengharuskan buruh datang dengan tepat waktu, waktu yang tersedia untuk istirahat kurang serta lamanya jam kerja di tempat kerja. Selain kedisiplinan waktu, kondisi lingkungan fisik dapat membuat buruh merasa tertekan seperti luas ruangan, pertukaran udara, pencahayaan, kebersihan, banyak gangguan, dan ketika atasan memberikan penilaian serta pengawasan terhadap hasil kerja yang dilakukan.

Sumber stres yang berasal dari lingkungan keluarga juga yang membuat buruh perempuan merasa tertekan. Hal yang membuat buruh perempuan tertekan dan stres adalah sedikitnya waktu yang tersedia untuk istirahat di rumah, karena harus mengerjakan tugas rumah tangga dan mengurus anak bagi yang telah menikah. Selain itu, adanya komunikasi yang tidak baik dengan anggota keluarga lainnya dan tidak terlibat dalam proses pengambilan keputusan dalam keluarga, sehingga buruh perempuan mengalami kekesalan di dalam keluarga. Hal inilah yang menyebabkan stres bagi buruh perempuan kaitannya dengan konflik peran ganda antara pekerjaaan dan keluarga. Hasil penelitian ini menguatkan hasil penelitian sebelumnya yang dilakukan oleh Ahmad (1995) dan Marettih (2013) bahwa konflik peran ganda erat kaitannya dengan munculnya gangguan kecemasan, depresi, dan perasaan bersalah, terutama pada perempuan yang memiliki anak. 
Buruh perempuan menikah dapat memanfaatkan waktu semaksimal mungkin agar dapat membagi waktu, baik bersama keluarga dan pekerjaan sebisa mungkin serta komunikasi yang baik dengan anggota keluarga lainnya agar tidak terjadi perselisihan di dalam keluarga. Hasil penelitian ini menguatkan hasil penelitian sebelumnya yang dilakukan oleh Gutek, Searle, dan Klepa, (1991); Gowan (1998) bahwa banyaknya waktu yang dicurahkan untuk menjalankan pekerjaan menghalangi seseorang untuk menjalankan kewajiban di rumah atau urusan keluarga. Hasil penelitian Duxbury dan Higgins (1991) mengatakan bahwa paling sedikit seperempat dari tantangan yang dihadapi oleh perusahaanperusahaan di Kanada adalah adanya tuntutan untuk menyeimbangkan antara urusan rumah tangga dan urusan pekerjaan yang pada akhirnya dapat menurunkan tingkat stres kerja karyawan. Persepsi keluarga dalam memberikan makna terhadap stressor dapat berpengaruh terhadap kemampuan keluarga dalam mengelola stres (Koswara, 2009).

Hasil penelitian menemukan bahwa pendapatan per kapita berpengaruh signifikan terhadap menurunnya tingkat stres buruh perempuan. Hal ini berarti bahwa bertambahnya pendapatan per kapita per bulan dapat menurunkan tingkat stres buruh perempuan. Hal ini dapat dijelaskan dengan meningkatnya buruh perempuan masuk ke dalam pasar tenaga kerja akan menghasilkan upah yang berkontribusi terhadap meningkatnya pendapatan per kapita keluarga. Temuan ini menguatkan hasil penelitian sebelumnya yang dilakukan oleh Latifah dan Juanda (2010) bahwa semakin bertambahnya pendapatan per kapita per bulan keluarga maka semakin baik strategi koping yang dilakukan untuk menghadapi permasalahan yang dialaminya.

Selain itu, strategi koping dimensi emotional focus coping yang berpengaruh signifikan terhadap menurunnya tingkat stres buruh perempuan. Hal ini berarti bahwa peningkatan strategi koping dimensi emotional focus coping yang dilakukan dapat menurunkan tingkat stres buruh perempuan. Strategi koping dimensi emotional focus coping yang dilakukan buruh perempuan memengaruhi seorang buruh perempuan dalam penataan emosi diri terhadap masalah yang dihadapi baik dari lingkungan pekerjaan maupun lingkungan keluarga dengan cara pengontrol diri dan menciptakan jarak. Perempuan bekerja mampu menentukan strategi pengatasan masalah apa yang akan digunakan sebagai cara penyelesaian terhadap masalah yang dihadapi, terutama masalah yang disebabkan oleh keluarga dan pekerjaan.

Penyelesaian terhadap masalah baik keluarga dan pekerjaan tergantung pada kepribadian seseorang dan sejauh mana tingkat stres dari kondisi yang dialami dan kemudian baru melakukan strategi mana yang paling sesuai dengan kondisi tersebut. Hasil ini juga memperkuat pernyataan dari Atkinson et al., (2000); Rotondo, Carlson, dan Kincaid (2002) bahwa seseorang yang cenderung menggunakan strategi terfokus masalah dalam mengatasi stres menunjukkan tingkat depresi yang lebih rendah baik selama dan setelah situasi stres, sedangkan strategi terfokus emosi dengan tujuan dapat menguasai diri dan melakukan tindakan untuk memecahkan masalah. Chu dan Chao (2011) meneliti manajemen stres dan memelihara ketenangan diri ditinjau dari aspek dukungan sosial dan koping strategi. Dukungan dari pasangan hidup dan keluarga lebih berperan dalam melakukan emotional focus coping karena keluarga menciptakan penilaian positif memberikan kontribusi pada kemampuan anggota keluarga untuk menghadapi stres.

\section{SIMPULAN DAN SARAN}

Usia, pendapatan responden, dan pendapatan per kapita pada buruh perempuan menikah lebih tinggi dibandingkan dengan buruh perempuan lajang. Sumber stres dan strategi koping buruh perempuan menikah lebih tinggi dibandingkan dengan buruh perempuan lajang dan sama-sama berada pada kategori sedang. Buruh perempuan yang lajang memiliki tingkat stres yang lebih tinggi dibandingkan dengan buruh perempuan menikah dan samasama berada pada sebaran kategori rendah. Peningkatan pendapatan per kapita dan strategi koping dimensi emotional focus coping berpengaruh terhadap penurunan tingkat stres buruh perempuan.

Berdasarkan hasil penelitian terdapat beberapa saran yang dapat diberikan, yaitu sebagai berikut: (1) buruh perempuan sebaiknya diberi pengetahuan tentang menyeimbangkan kehidupan dari lingkungan pekerjaan dan keluarga (balancing work and family), (2) keluarga dapat memberikan dukungan emosional yang baik dan saling membantu pekerjaan di dalam lingkungan keluarga agar tidak terjadi gejala penyakit yang dapat berakibat stres tersendiri bagi buruh perempuan dalam bekerja, (3) pemerintah melalui dinas ketenagakerjaan melakukan monitoring terhadap pabrik yang memper- 
kerjakan buruh perempuan agar menerapkan kewajiban perusahaan terhadap tenaga kerjanya yang harus dipenuhi sesuai dengan Undang-undang Ketenagakerjaan.

\section{DAFTAR PUSTAKA}

Ahmad, A. (1995). Role conflict and coping behavior of working women. Pertanika $J$ Social, Journal of Science and Humaniora, 3, 97-104.

Atkinson., Atkinson., Smith., \& Bem. (2000). Pengantar psikologi. Edisi ke-11, Jilid kedua. Jakarta, ID: Interaksara.

Burke, R. J. (1994). Stressful events, workfamily conflict, coping, psychological burnout and well-being among police officers. Journal of Psychological Reports, 75, 787-800.

Burke, R. J., \& Greenglass, E. R. (2001). Hospital restructuring, work-family conflict and burnout among nursing staff. Journal of Psychology and Health, 16, 583-594.

Carlson, D. W., \& Perrewe, P. L. (1999). The role of social support in the stressor strain relationship: An examination of work-family conflict. Journal of Management, 25(4), 513-540.

Chu, R., \& Chao, L. (2011). Managing stress and maintaining well-being: social support, problem focus coping, and avoidant coping. Journal of Counceling and Development, pg 338. USA: University of Danver.

Duxburry, L. E., \& Higgins, C. A. (1991). Gender differences in work family conflict. Journal of Applied Psychology, 76, 60-74.

Greenhaus, J. H., \& Beutell, N. J. (1985). Sources of conflict between work and family roles. Academy of Management Review, 10(1), 76-88.

Gowan, M. (1998). An examination of gender differencesi Mexican-American attitudes toward family and career roles. Sex Roles: A Journal of Research. Diambil dari http://www.looksmart.com.

Gutek, B. A., Searle, S., \& Klepa, L. (1991). Rational versus gender role explanations for work-family conflict. Journal of Applied Psychology, 76(4), 560-568.

Hutagalung, Nurmala, K., Grijns M., \& Benyamin, White. (1992). Wanita sebagai buruh. Proyek Penelitian sektor nonpertanian pedesaan Jawa Barat. PSPIPB.
Kossek, E. E., \& Ozeki, C. (1999). Bridging the work-family policy an productivity gap: A literature review. Community Work and Family, 2, 7-32.

Koswara, H. (2009). Pengaruh stres pekerjaan terhadap keberfungsian keluarga pekerja di Kota Bandung (Tesis). Departemen Gizi Masyarakat dan Konsumen, Fakultas Ekologi Manusia, Sekolah Pascasarjana Institut Pertanian Bogor, Bogor.

Latifah, M., \& Juanda, A. M. (2010). Penerimaan, tingkat stres, dan strategi koping ibu terhadap program konversi minyak tanah ke LPG di Kabupaten Bogor. Jur. IIm. Kel. \& Kons., 3(2), 133-139.

Lazarus, R. S., Folkman, S., Schhetter, C. H., DeLongis, A., \& Gruen, R. J. (1986). Dynamics of a stressful encounter: cognitive apraisal, coping, and encounter outcomes. Journal of Personality and social Pstchology, 50(5), 99-1003.

Marettih, A. K. E. (2013). Family conflict pada ibu bekerja (studi fenomena perspektif gender dan kesehatan mental. Journal Sosial Budaya, 10(1).

Puspitawati, H., Simanjuntak, M., \& Hayati, L. (2012). Kontribusi dan peran ganda perempuan serta pengaruhnya terhadap kesejahteraan subjektif. Jur. IIm. Kel. \& Kons., 5(2), 11-18.

Rotondo, D. M., Carlson, D. S., \& Kincaid, Kincaid, J. F. (2002). Coping with multiple dimensions of work-family conflict. Journal of Personnel Review, 32(3), 275-296.

Safarino, E. P. (1994). Health Psychology: Biopsychological Interactions (2nd Ed). New York, US: John Wiley dan Sons, Inc.

Sasono, E. (2004). Mengelola stres kerja. Journal ekonomi, 3(2) Agustus, 121-128.

Smet, B. (1994). Psikologi kesehatan. Jakarta, ID: PT Gramedia Widiasarana Indonesia.

Sussman, M. B., \& Steinmetz, S. K. (1987). Handbook of Marriage and the Family. New York, US: Plenum Press.

Tambunan, R. O. (2007). Buruh perempuan indonesia dan gejala globalisasi. Jurnal Perempuan, 61. Jakarta, ID: Yayasan Jurnal Perempuan.

Thomas, L. T., \& Gaster, D. C. (1995). Impact of family-supportive variables on workfamily conflict and strain: A control perspective. Journal of Applied Psychology, 80(1), 6-15. 
Wells-Parkers, E., Miller, D. L., \& Topping, J. S. (1990). Development of control of outcome scale and self efficacy scale for women in four life roles. Journal of Personality Assessment, 54, 564-575.

Yang, N., Chen, C. C., \& Zou, Y. (2000). Sources of work-family conflict; A Sino-US comparison of the effects of work and family demands. Journal of Academy Management, 43(1), 113-123.

Zakowski, S. G., Hall, M. H., Klein, Baum. (2001). Appraised control, coping and stress in community sample: A test of the goodness of fit hypothesis. Journal of Behavior Medicine, 23, 158-165. 